\title{
Iron Doped SBA-15 Mesoporous Silica Studied by Mössbauer Spectroscopy
}

\author{
Lukasz Laskowski, ${ }^{1}$ Magdalena Laskowska, ${ }^{1}$ Jerzy Jelonkiewicz, ${ }^{1}$ Tomasz Galkowski, \\ Piotr Pawlik, ${ }^{2}$ Henryk Piech, ${ }^{3}$ and Marek Doskocz ${ }^{4}$ \\ ${ }^{1}$ Institute of Computational Intelligence, Czestochowa University of Technology, Aleja Armii Krajowej 36, 42-201 Czestochowa, Poland \\ ${ }^{2}$ Institute of Physics, Czestochowa University of Technology, Aleja Armii Krajowej 19, 42-201 Czestochowa, Poland \\ ${ }^{3}$ Institute of Computer Science, Czestochowa University of Technology, Ulica Dobrowskiego 69, 42-201 Czestochowa, Poland \\ ${ }^{4}$ Rootinnovation Spółka z o.o., Ulica Matejki 11/1a, 50-016 Wrocław, Poland
}

Correspondence should be addressed to Łukasz Laskowski; lukasz.laskowski@kik.pcz.pl

Received 8 January 2016; Accepted 17 March 2016

Academic Editor: Pushpendra Kumar

Copyright (C) 2016 Łukasz Laskowski et al. This is an open access article distributed under the Creative Commons Attribution License, which permits unrestricted use, distribution, and reproduction in any medium, provided the original work is properly cited.

\begin{abstract}
Mesoporous silica SBA-15 containing propyl-iron-phosphonate groups were considered to confirm their molecular structure. To detect the iron-containing group configuration the Mössbauer spectroscopy was used. Both mesoporous silica SBA-15 containing propyl-iron-phosphonate groups and pure doping agent (iron acetylacetate) were investigated using Mössbauer spectroscopy. The parameters such as isomer shift, quadrupole splitting, and asymmetry in ${ }^{57} \mathrm{Fe}$ Mössbauer spectra were analyzed. The differences in Mössbauer spectra were explained assuming different local surroundings of Fe nuclei. On this base we were able to conclude about activation of phosphonate units by iron ions and determinate the oxidation state of the metal ion. To examine bonding between iron atoms and phosphonic units the resonance Raman spectroscopy was applied. The density functional theory (DFT) approach was used to make adequate calculations. The distribution of active units inside silica matrix was estimated by comparison of calculated vibrational spectra with the experimental ones. Analysis of both Mössbauer and resonance Raman spectra seems to confirm the correctness of the synthesis procedure. Also EDX elemental analysis confirms our conclusions.
\end{abstract}

\section{Introduction}

Recently, many research efforts have been focused on design and synthesis of functional materials based on porous silica matrix and transition metal-containing active groups not only due to their attractive architectures but also for potential applications [1-6]. A wide synthesis activity enabled the synthesis routines control of the mesoporous silica with variable size $(2-20 \mathrm{~nm})$ of pores. Additionally, several functional groups grafted either in the pores or in the wall structures were successfully obtained [7-9]. The synthesis of such samples which would contain the functional groups homogeneously distributed in the host matrices is still the main challenge. These functional groups, if successfully anchored in the silica-based architecture, can offer fine-tuned physical properties (electronic, magnetic, and optical).
The paper concerns the mesoporous silica SBA-15 functionalised by the propyl-iron-phosphonate units. The molar concentration of the propyl-iron-phosphonate units in the silica matrix is $10 \%$ (1 silano-propyl-Fe-phosphonate group per $9 \mathrm{SiO}_{2}$ groups). Our intention is to report an original approach to probing the synthesis efficiency, in particular, the activation efficiency and homogeneity of the active units distribution. The molecular structure of the species was detected using Mössbauer spectroscopy and confirmed by Raman scattering supported by DFT simulations. As a complementary research we carried out EDX elemental analysis.

Mössbauer spectroscopy is very useful to study structural and physical properties of many inorganic and organic materials, especially iron-containing species. Mössbauer parameters deliver valuable information about the electronic configuration of ${ }^{57} \mathrm{Fe}$ atoms and their surroundings. On the base of 
comparative analysis of the Mössbauer spectroscopy carried out for the pure doping agent and target compound it is possible to determine whether the transition of phosphonate units into iron-phosphonate units occurred. Moreover we were able to determine the oxidation state of the iron ion. The electronic state of the iron ion, obtained in the Mössbauer spectroscopy, was confirmed by the EPR spectroscopy.

The Raman scattering measurements combined with numerical models seem to be an adequate approach to check the correctness of molecular configurations in the samples. The assignment of bands in the experimental Raman spectrum is necessary to detect the spectral changes in the hydrogen-bonded active groups. Moreover the EDX elemental analysis helps you find the correct molar proportions between key radicals.

\section{Materials and Methods}

Synthesis of the mesoporous silica SBA-15 functionalised by propyl-phosphate-iron units was done by cocondensation of tetraethylorthosilicate (TEOS) and phosphonatepropyltriethoxysilane (PPTES) with presence of surfactant (Pluronic P123). The main part of the procedure was described in detail in our previous work $[10,11]$ with one difference: the iron(II) acetylacetonate $\left(\mathrm{Fe}(\mathrm{acac})_{2}\right)$ was used as the doping agent. Resulting iron-containing SBA-15 silica compound is called SBA-propyl- $\mathrm{POO}_{2} \mathrm{Fe}$.

The ${ }^{57} \mathrm{Fe}$ Mössbauer spectra of powdered samples were recorded at room temperature with a ${ }^{57}$ Co source (Rh matrix) in transmission geometry. The velocity was calibrated using a $\alpha$-Fe foil. Mössbauer spectra were analyzed by the leastsquare fitting of Lorentzian lines using the Normos program [12].

For the spin state confirmation of the iron ions we measured our samples with EPR spectrometer. EPR measurements were conducted on a Bruker EMX continuous-wave (CW) X-band $(9.5 \mathrm{GHz})$. The spectra were recorded with microwave power in the range of $20-200 \mathrm{~mW}$ using magnetic field modulation of about $5 \mathrm{G}$. EPR measurements at variable temperatures $(10-300 \mathrm{~K})$ were performed by an Oxford Instruments cryostat.

Resonance Raman measurements were carried out at room temperature in the range from 300 to $4000 \mathrm{~cm}^{-1}$. A Raman spectrometer (Nicolet Almega XR) was equipped with a Nd:YAG laser. The experiments were carried out at $532 \mathrm{~nm}$ and the laser was operated at a power level of $40 \mathrm{~mW}$. The spectral resolution of the spectrometer was equal to $1 \mathrm{~cm}^{-1}$. The same experimental conditions were kept for all the investigated samples.

DFT simulations were carried out in order to find characteristic Raman bands. All theoretical calculations were carried out using the GAUSSIAN 09 package [13] with default convergence criteria applied. The geometry of the model molecule enriched of metal ion was fully optimized at the level of B3LYP [14] with the 6-31G(d,p) basis set, as the most suitable for metal-containing SBA-15 silica model. After geometry optimization, the Raman vibrational modes were calculated using the same method and basis set.
TABLE 1: Mössbauer parameters (in $\mathrm{mm} / \mathrm{s}$ ) derived from experimental spectra of the complexes studied.

\begin{tabular}{lcc}
\hline & $\mathrm{Fe}(\mathrm{acac})_{2}$ & SBA-prop- $\mathrm{POO}_{2} \mathrm{Fe}$ \\
\hline QS & 0.842 & 0.738 \\
IS & 0.381 & 0.397 \\
$\Gamma$ & 0.499 & 0.648 \\
\hline
\end{tabular}

The assignment of the calculated Raman bands was done on the basis of PED analysis $[15,16]$ and aided by the animation option of the GaussView 5.0 graphical interface for Gaussian programs [17], which gave a visual representation of the vibrational modes shape. As far as PED analysis is concerned, the calculations were carried out in VEDA software [18]. By combining the results of the visualization with potential energy distribution (PED) we obtained very accurate description of the molecules vibrations. The procedure was described in detail in [19].

The EDX quantitive elemental analysis was carried out using the FEI Tecnai G2 20 X-TWIN electron microscope, equipped with emission source LaB6, CCD camera FEI Eagle $2 \mathrm{~K}$, and X-Ray microanalyzer EDX.

\section{Results and Discussion}

The main problem occurring during synthesis of functionalised SBA-15 mesoporous silica lies in the homogeneous distribution of functional groups. The key stage in the synthesis of this functional material is the functionalisation of precursor groups (propyl-phosphonic acid) by doping agents $\left(\mathrm{Fe}(\mathrm{acac})_{2}\right)$. The one-step synthesis of SBA-15 silica containing precursor groups is not treated as a critical point of the synthesis. The cocondensation method guarantees the homogeneity of distribution of precursor groups in the silica matrix. Nevertheless we are able to probe the key stage of the synthesis route by using of molecular spectroscopy methods: Mössbauer and Raman.

The Mössbauer spectra were recorded for two kinds of samples: mesoporous silica containing propyl-Fe-phosphate groups and $\mathrm{Fe}(\mathrm{acac})_{2}$ as the doping agent. In the case of full activation (each precursor group activated by iron) the environment of Fe ions should be different in comparison with the environments in the doping agent, and the differences in the environments should be reflected in Mössbauer spectra. Both spectra (Figure 1) were compared taking into account isomer shifts (IS), quadrupole splitting (QS), line widths $(\Gamma)$ (Table 1), and the asymmetry of the doublets.

The parameters collected in Table 1 seem not to vary significantly for both samples; however, the detailed analysis reveals some important differences. The IS and QS values can indicate the high-spin $\mathrm{Fe}^{3+}$ oxidation state $[20,21]$ or low-spin $\mathrm{Fe}^{2+}$ state [22]. The doping agent $\left(\mathrm{Fe}(\mathrm{acac})_{2}\right)$ was a commercial product purchased from Sigma-Aldrich as a high-purity compound in oxidation state $2+$, so the most probable state of iron ions is $\mathrm{Fe}^{2+}, S=0$. The EPR research did not show any signal in the temperature range from 10 to $300 \mathrm{~K}$, which can confirm that our sample contains ferrous ions with spin $S=0$. Both spectra show the relatively 


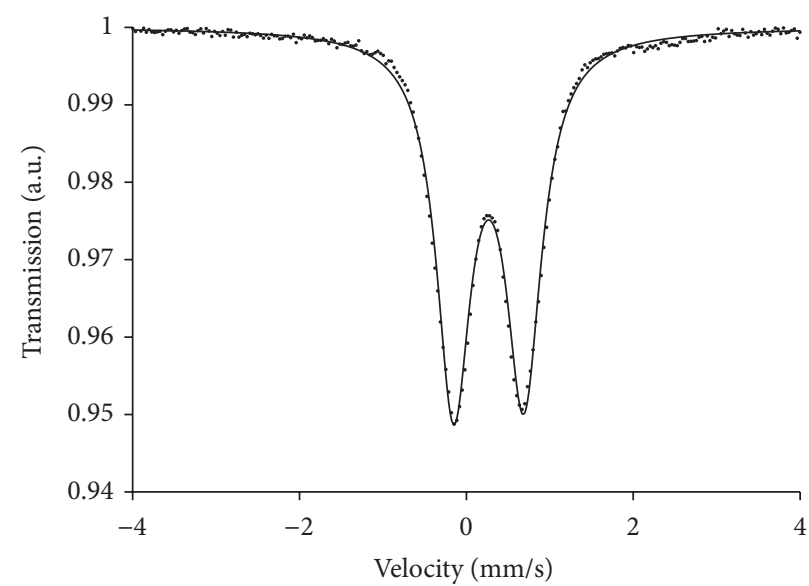

(a)

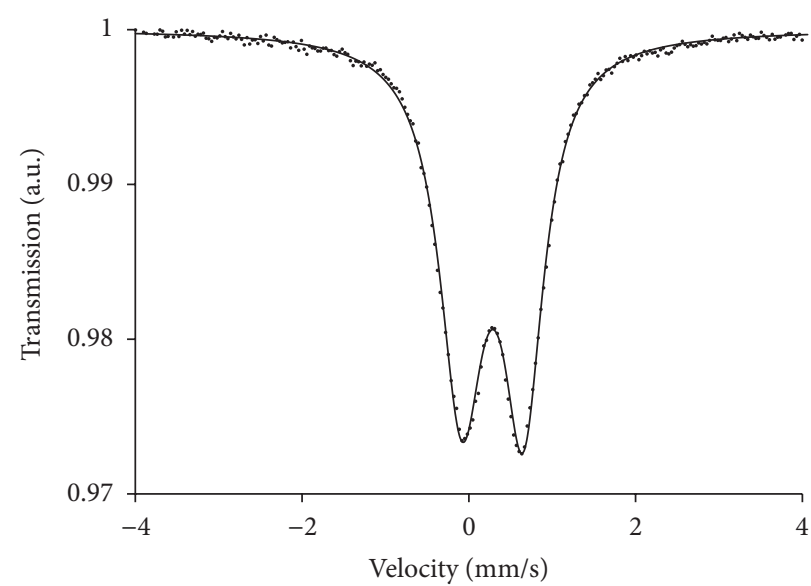

(b)

FIgURE 1: Mössbauer spectra at room temperature: (a) Fe(acac) $)_{2}$, (b) SBA-prop- $\mathrm{POO}_{2} \mathrm{Fe}$.

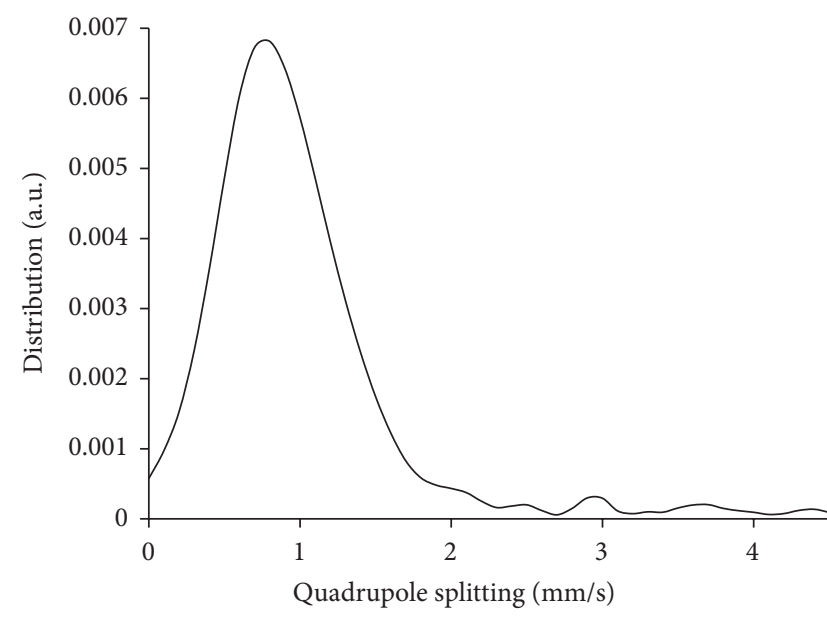

(a)

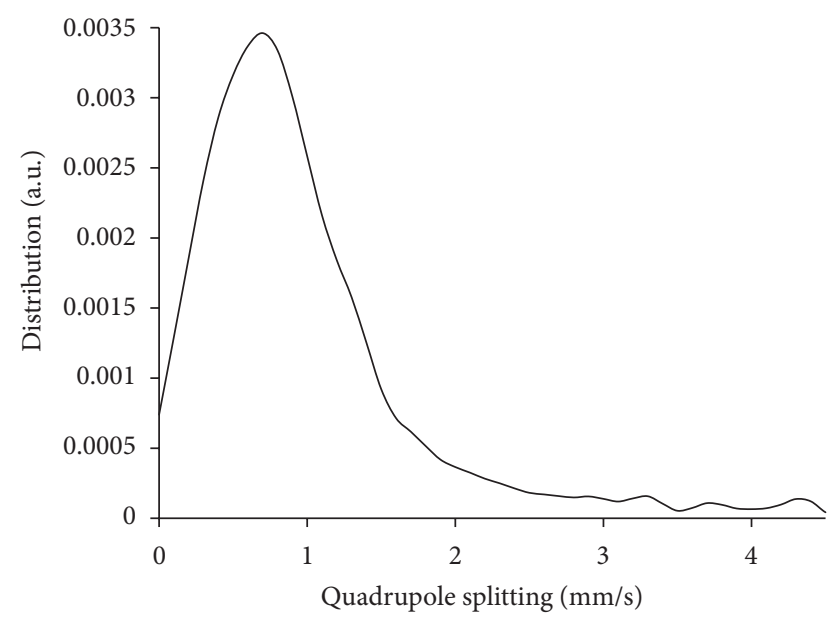

(b)

FIgURE 2: Distribution of quadrupole splittings for (a) Fe(acac) $)_{2}$ and (b) SBA-propyl- $\mathrm{POO}_{2} \mathrm{Fe}$.

high values of the line widths. Such a broadening can arise mainly from relaxation effects or from isomer shift and quadrupole splitting distributions. In this paper we consider the quadrupole splitting distribution, with the assumption of linear dependence between the IS and QS values. The use of the distribution procedure applied in the Normos package which gave the QS distributions is shown in Figure 2.

We can see one intensive broad peak and a few smallintensity peaks for higher values of the quadrupole splitting. The latter small peaks can be connected with the relatively long "wings" in the Mössbauer spectra (Figure 1) and they do not have a physical meaning. The intensive broad peaks in the distributions (Figure 2) indicate that each sample contains iron ions with the same electron configuration (in this case: $\mathrm{Fe}^{2+}, S=0$ ) and continuously distributed quadrupole splittings caused by distribution of the electric field gradient (EFG) around $\mathrm{Fe}^{2+}$ ions. Local distortions of bond lengths and angles can lead to wide range of local environments of $\mathrm{Fe}^{2+}$ ions and next to the continuous distribution of quadrupole splittings. Different kinds of asymmetry observed in the spectra (Figures 1(a) and 1(b)) can be connected with varying values of the linear parameters in the relationship IS $=f(\mathrm{QS})$ for the mesoporous silica containing propyl-Fephosphate groups and $\mathrm{Fe}(\mathrm{acac})_{2}$ samples. A slight shoulder observed in the distribution for SBA-propyl- $\mathrm{POO}_{2} \mathrm{Fe}$ spectrum (Figure 2(b)) indicates contribution of additional doublet from the doping agent $\mathrm{Fe}(\mathrm{acac})_{2}$. We tried to fit the SBApropyl- $\mathrm{POO}_{2} \mathrm{Fe}$ spectrum (Figure $1(\mathrm{~b})$ ) by two doublets and, taking into account the areas under the doublets, we found that contribution of the doping $\mathrm{Fe}(\mathrm{acac})_{2}$ is negligible (less than $0.1 \%$ ). It means that practically all propyl-phosphonic acid precursor groups were functionalised by the $\mathrm{Fe}(\mathrm{acac})_{2}$ agents (two different surroundings of iron ions in samples).

The Raman spectroscopy supported by numerical simulations fully confirms the results presented above. The indepth analysis of this case was available in [19]; therefore we present only a brief overview of the results. Two samples were analyzed under this technique: SBA-15 mesoporous silica 


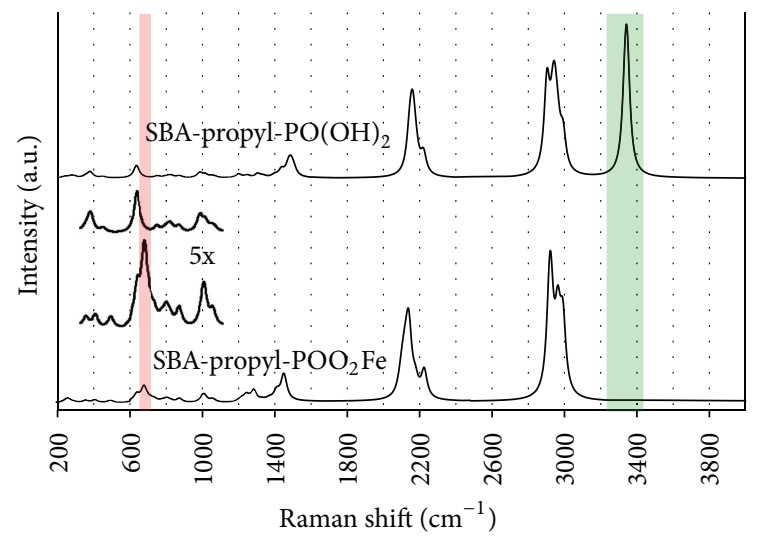

(a)

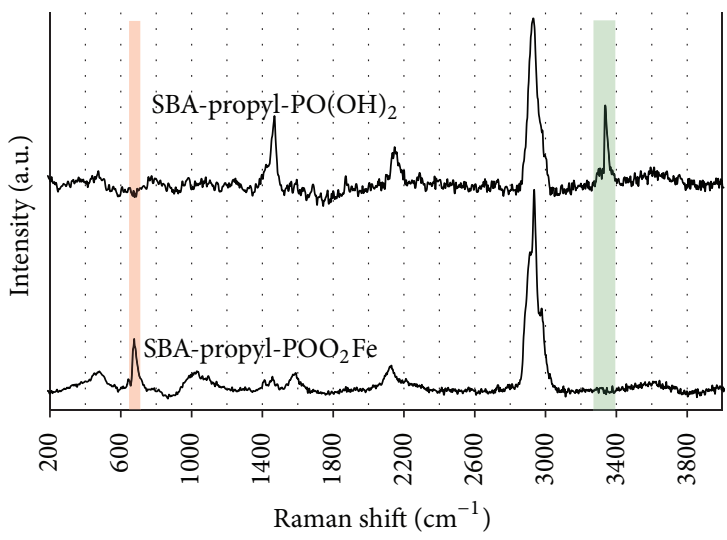

(b)

Figure 3: The juxtaposition of the Raman spectra for silica containing propyl-phosphonic acid and propyl-iron-phosphonate units, theoretically calculated (a) and experimental (b). Main characteristic bands (bands appearing in only one species) are marked as coloured bands.

containing propyl-phosphonic acid groups (SBA-propyl$\left.\mathrm{PO}(\mathrm{OH})_{2}\right)$ as the reference and SBA-15 mesoporous silica containing propyl-iron-phosphate groups (SBA-propyl$\mathrm{POO}_{2} \mathrm{Fe}$ ). Both samples were obtained during the same synthesis route, but in other steps (SBA-15 containing propylphosphonic acid groups are a precursor of a SBA-15 containing propyl-Fe-phosphate groups). The DFT simulations for models of considered molecules enabled the precise identification of the vibrations origins. Characteristic Raman frequencies were found by comparison of theoretically calculated spectra (DFT method) and selecting peaks that are different for both samples. We expect that, for successful functionalisation, each propyl-phosphonic acid group will be transferred into propyl-iron-phosphate group. As a result we should find in the spectrum of SBA-propyl- $\mathrm{PO}(\mathrm{OH})_{2}$ features originated from propyl-phosphonic acid groups, which are not present in the spectrum of SBA-prop- $\mathrm{POO}_{2} \mathrm{Fe}$. And, vice versa, in the spectrum of SBA-propyl- $\mathrm{POO}_{2} \mathrm{Fe}$ we should find peaks created by the propyl-iron-phosphate groups vibration, which should be invisible for the SBA-propyl- $\mathrm{PO}(\mathrm{OH})_{2}$ spectrum. The juxtaposition of the theoretical Raman spectra with the experimental ones for considered samples can be seen in Figure 3(a) (theoretically calculated) and in Figure 3(b) (experimental).

The most significant theoretical vibrations for SBApropyl- $\mathrm{PO}(\mathrm{OH})_{2}$ are located within $3320-3380 \mathrm{~cm}^{-1}$ region while SBA-propyl- $\mathrm{POO}_{2} \mathrm{Fe}$ displays peak at $670 \mathrm{~cm}^{-1}$. The first one comes from the $\mathrm{O}-\mathrm{H}$ stretching modes of the phosphonic acid groups in SBA-propyl-PO $(\mathrm{OH})_{2}$. The ironcontaining species vibration at $667 \mathrm{~cm}^{-1}$ can be assigned to deformation of the propyl-iron-phosphate unit. The analysis of these regions in experimental spectra can give information about the synthesis efficiency.

Indeed, in the experimental spectra of the ironcontaining specimen we can observe distinguishable peaks at $674 \mathrm{~cm}^{-1}$ coming from complex vibration of the propylFe-phosphate group. For SBA-propyl- $\mathrm{PO}(\mathrm{OH})_{2}$ the region
TABLE 2: EDX quantification results of SBA-15 mesoporous silica containing $10 \%$ of propyl-iron-phosphate units (SBA-prop$\left.\mathrm{POO}_{2} \mathrm{Fe}\right)$.

\begin{tabular}{lccc}
\hline Element & Weight $\%$ & Atomic $\%$ & Uncertainty \% \\
\hline $\mathrm{C}(\mathrm{K})$ & 49.11 & 66.88 & 0.52 \\
$\mathrm{O}(\mathrm{K})$ & 21.59 & 22.08 & 0.19 \\
$\mathrm{Si}(\mathrm{K})$ & 9.93 & 5.78 & 0.09 \\
$\mathrm{P}(\mathrm{K})$ & 1.02 & 0.54 & 0.02 \\
$\mathrm{Fe}(\mathrm{K})$ & 1.68 & 0.49 & 0.04 \\
$\mathrm{Cu}(\mathrm{K})$ & 16.26 & 4.23 & 0.14 \\
\hline
\end{tabular}

within $640-1300 \mathrm{~cm}^{-1}$ seems to be flat. This indicates that iron is joined through the propyl-phosphate groups in the silica matrix.

In the case of SBA-propyl-PO $(\mathrm{OH})_{2}$ the well-resolved peak can be observed at about $3350 \mathrm{~cm}^{-1}$. These vibrations can be assigned to stretching modes of the phosphonic acid groups, particularly, asymmetrical stretching of hydroxy units. The region above $3100 \mathrm{~cm}^{-1}$ did not contain any Raman bands in the case of the SBA-propyl- $\mathrm{POO}_{2} \mathrm{Fe}$, which can prove the absence of the phosphonic acid groups in this sample. This is the result of the complete functionalisation; phosphonic acid groups are not present in the sample.

The quantitive EDX analysis was carried out for ironcontaining silica sample as a supplementary research, in order to confirm our previous results. The EDX spectrum is shown in Figure 4 and quantification results are presented in Table 2.

It is clearly seen that the SBA-prop- $\mathrm{POO}_{2} \mathrm{Fe}$ sample has almost assumed quantity of iron; the molar ratio of silicon to phosphorous and silicon to iron is equal to 10.707 and 11.815, respectively. This lead to a conclusion that almost each phosphonic acid group was activated by iron. Minor deficiency of iron is caused by propyl-phosphonic acid groups incorporated in silica walls. 


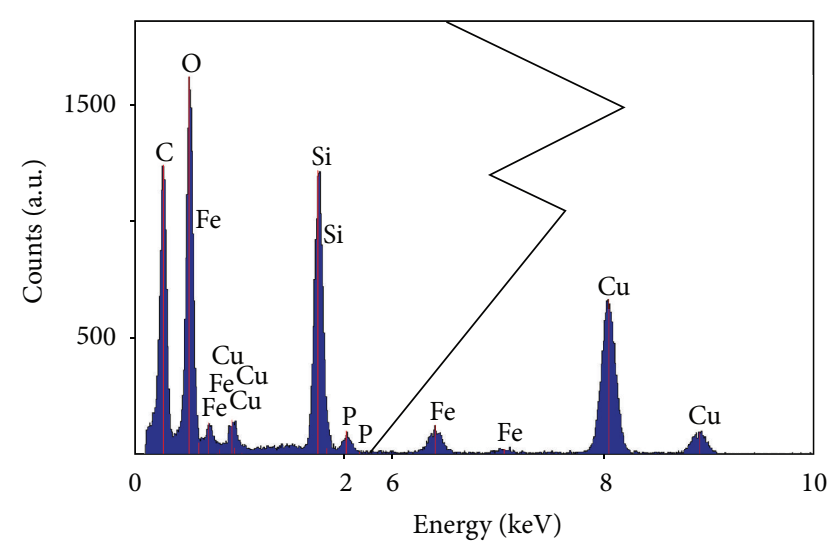

FIGURE 4: The EDX spectra of SBA-prop- $\mathrm{POO}_{2} \mathrm{Fe}$ sample. For better visibility, region between 2 and $6 \mathrm{keV}$ (no peak observed) has been removed.

\section{Conclusion}

The Mössbauer spectroscopy was applied to examine the functionalisation efficiency of the iron-containing mesoporous silica SBA-15. This SBA-15 containing propyl-ironphosphate was investigated in comparison with $\mathrm{Fe}(\mathrm{acac})_{2}$ as the doping agent. Comparative analysis of the spectra and obtained parameters has shown that for both investigated samples only one electron configuration of ferrous ions can be observed (there is no excess of the doping agent inside iron-containing mesoporous samples). Mössbauer parameters indicate low-spin $\mathrm{Fe}^{2+}(S=0)$ for both samples. The low-spin state of ferrous ions was also confirmed in the EPR spectroscopy. The abovementioned results show that the activation process runs according to synthesis assumptions and phosphonic acid groups are activated to iron-phosphate. The success of the activation process was also confirmed by Raman scattering supported by numerical simulations and EDX elemental analysis.

\section{Competing Interests}

The authors declare that they have no competing interests.

\section{Acknowledgments}

Financial support for this investigation has been provided by the National Centre of Science (Grant no. 2011/03/D/ ST5/05996).

\section{References}

[1] B. G. Trewyn, J. A. Nieweg, Y. Zhao, and V. S.-Y. Lin, "Biocompatible mesoporous silica nanoparticles with different morphologies for animal cell membrane penetration," Chemical Engineering Journal, vol. 137, no. 1, pp. 23-29, 2008.

[2] A. Katiyar, S. Yadav, P. G. Smirniotis, and N. G. Pinto, "Synthesis of ordered large pore SBA-15 spherical particles for adsorption of biomolecules," Journal of Chromatography A, vol. 1122, no. 1-2, pp. 13-20, 2006.
[3] I. I. Slowing, B. G. Trewyn, S. Giri, and V. S.-Y. Lin, "Mesoporous silica nanoparticles for drug delivery and biosensing applications," Advanced Functional Materials, vol. 17, no. 8, pp. 12251236, 2007.

[4] D. Jung and M. Hartmann, "Oxidation of Indole with CPO and GOx Immobilized on SBA-15," Studies in Surface Science and Catalysis, vol. 174, pp. 1045-1050, 2008.

[5] F.-S. Xiao, "Ordered mesoporous materials with improved stability and catalytic activity," Topics in Catalysis, vol. 35, no. 1-2, pp. 9-24, 2005.

[6] P. K. Jal, S. Patel, and B. K. Mishra, "Chemical modification of silica surface by immobilization of functional groups for extractive concentration of metal ions," Talanta, vol. 62, no. 5, pp. 1005-1028, 2004.

[7] R. Corriu, "Where organosilicon chemistry is going?" Journal of Organometallic Chemistry, vol. 686, no. 1-2, p. 1, 2003.

[8] R. Corriu, A. Mehdi, and C. Reyé, "Nanoporous materials: a good opportunity for nanosciences," Journal of Organometallic Chemistry, vol. 689, no. 24, pp. 4437-4450, 2004.

[9] L. Laskowski, A. Kassiba, M. Makowska-Janusik et al., "Magnetic behaviour of nickel-cyclam complexes in mesoporous silica: EPR investigations," Journal of Physics: Condensed Matter, vol. 21, no. 7, Article ID 076004, 2009.

[10] Ł. Laskowski, M. Laskowska, M. Bałanda et al., "Mesoporous silica SBA-15 functionalized by nickel-phosphonic units: Raman and magnetic analysis," Microporous and Mesoporous Materials, vol. 200, pp. 253-259, 2014.

[11] L. Laskowski and M. Laskowska, "Functionalization of SBA15 mesoporous silica by $\mathrm{Cu}$-phosphonate units: probing of synthesis route," Journal of Solid State Chemistry, vol. 220, pp. 221-226, 2014.

[12] R. A. Brant, Normos Mössbauer Fitting Program: Demo Version, Wissel gmbH, Stanberg, Germany, 1994.

[13] M. J. Frisch, G. W. Trucks, H. B. Schlegel et al., Gaussian 09, Gaussian, Wallingford, Conn, USA, 2009.

[14] W. Kohn and L. J. Sham, "Self-consistent equations including exchange and correlation effects," Physical Review A, vol. 140, no. 4, pp. A1133-A1138, 1965.

[15] M. H. Jamróz, J. C. Dobrowolski, and R. Brzozowski, "Vibrational modes of 2,6-, 2,7-, and 2,3-diisopropylnaphthalene. A DFT study," Journal of Molecular Structure, vol. 787, no. 1-3, pp. 172-183, 2006.

[16] M. Vakili, S. F. Tayyari, M. Hakimi-Tabar, A.-R. Nekoei, and S. Kadkhodaei, "Structure and vibrational assignment of bis(benzoylacetonato)copper(II)," Journal of Molecular Structure, vol. 1058, no. 1, pp. 308-317, 2014.

[17] R. Dennington, T. Keith, and J. Millam, Gaussview Version 5, Semichem Inc, Shawnee Mission, KS, USA, 2009.

[18] M. H. Jamróz, "Vibrational energy distribution analysis (VEDA): scopes and limitations," Spectrochimica Acta-Part A: Molecular and Biomolecular Spectroscopy, vol. 114, pp. 220-230, 2013.

[19] M. Laskowska, L. Laskowski, and J. Jelonkiewicz, "SBA-15 mesoporous silica activated by metal ions-verification of molecular structure on the basis of Raman spectroscopy supported by numerical simulations," Journal of Molecular Structure, vol. 1100, pp. 21-26, 2015.

[20] N. Chiwaye, L. L. Jewell, D. G. Billing, D. Naidoo, M. Ncube, and N. J. Coville, "In situ powder XRD and Mössbauer study of $\mathrm{Fe}-\mathrm{Co}$ supported on $\mathrm{CaCO}_{3}$," Materials Research Bulletin, vol. 56, pp. 98-106, 2014. 
[21] F. Ramezanipour, J. E. Greedan, A. P. Grosvenor, J. F. Britten, L. M. D. Cranswick, and V. O. Garlea, "Intralayer cation ordering in a brownmillerite superstructure: synthesis, crystal, and magnetic structures of $\mathrm{Ca}_{2} \mathrm{FeCoO}_{5}$," Chemistry of Materials, vol. 22, no. 21, pp. 6008-6020, 2010.

[22] N. N. Greenwood and T. C. Gibb, Mössbauer Spectroscopy, Springer, Dordrecht, The Netherlands, 1974. 

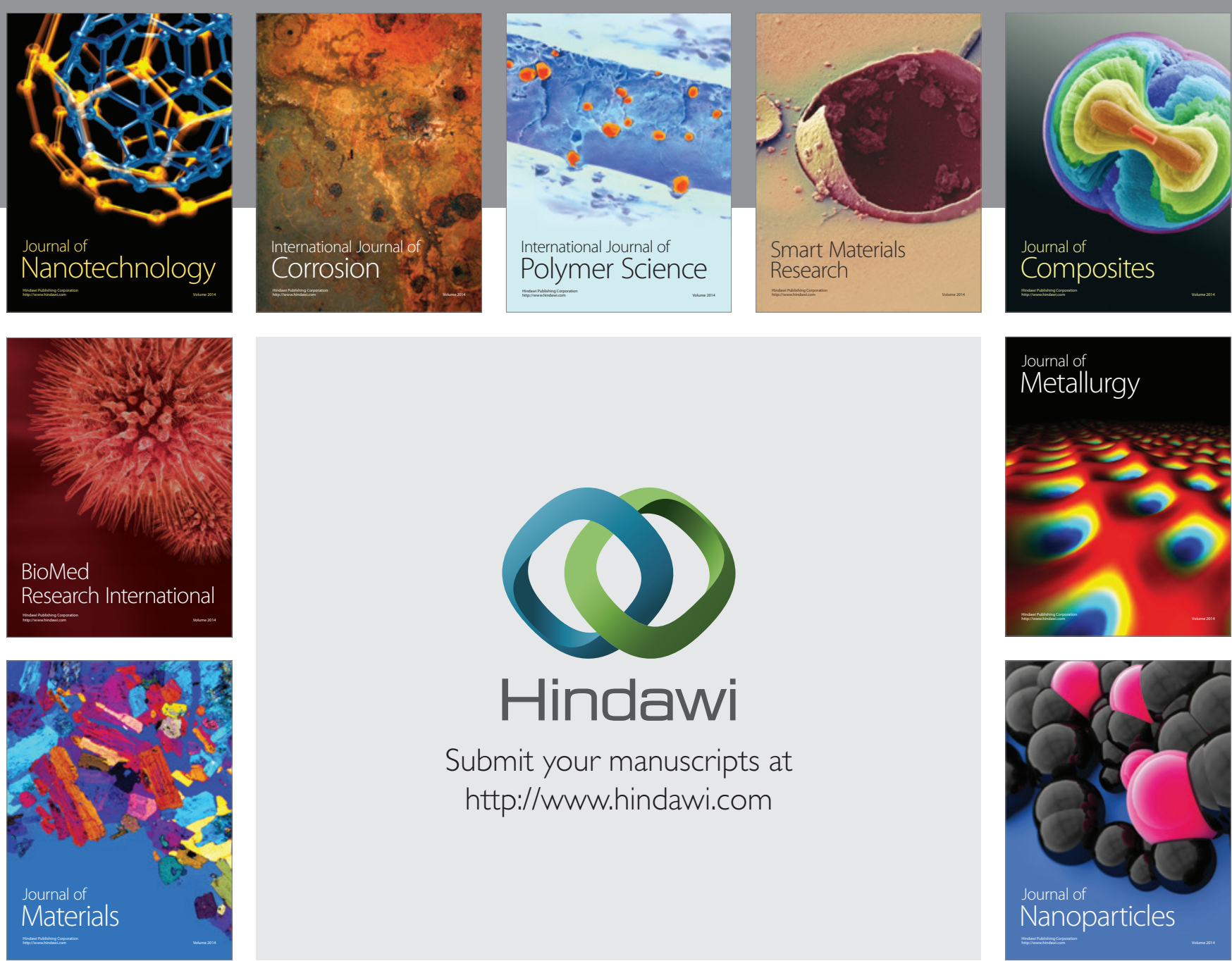

\section{Hindawi}

Submit your manuscripts at

http://www.hindawi.com

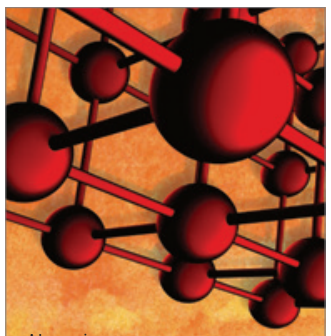

Materials Science and Engineering
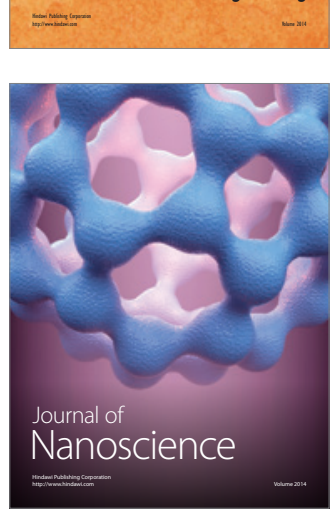
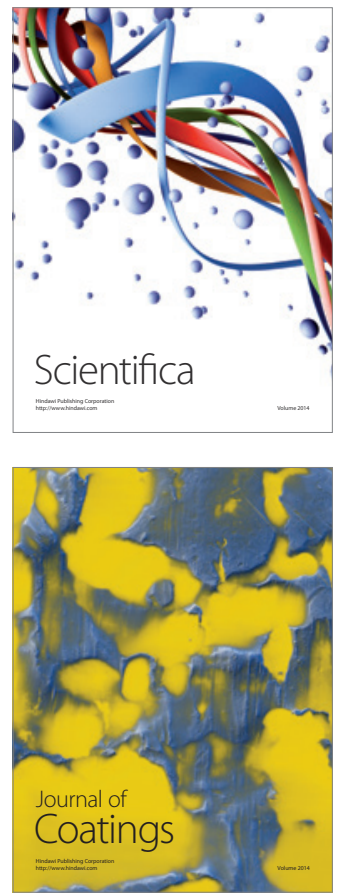
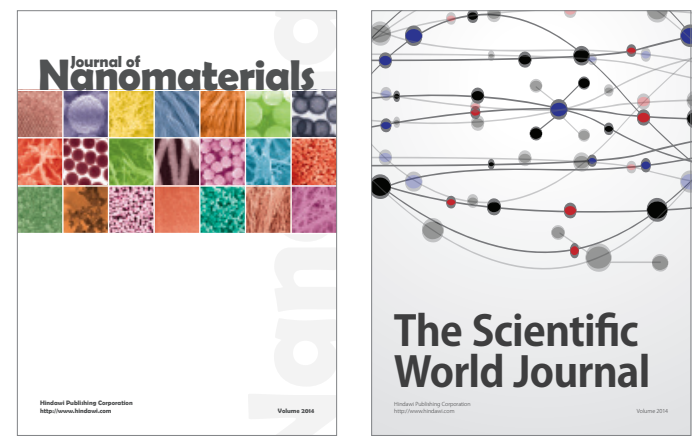

The Scientific World Journal
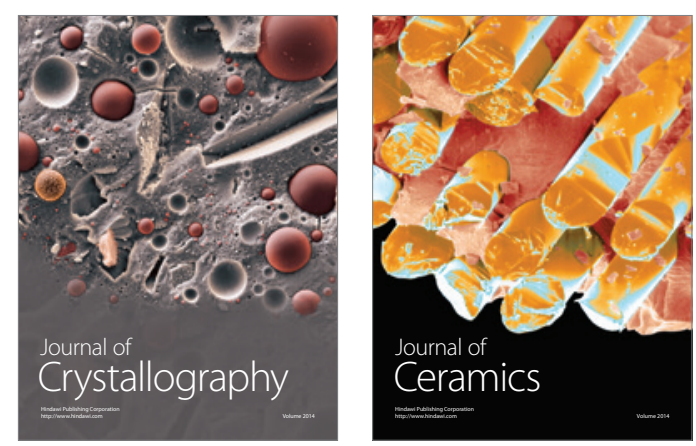
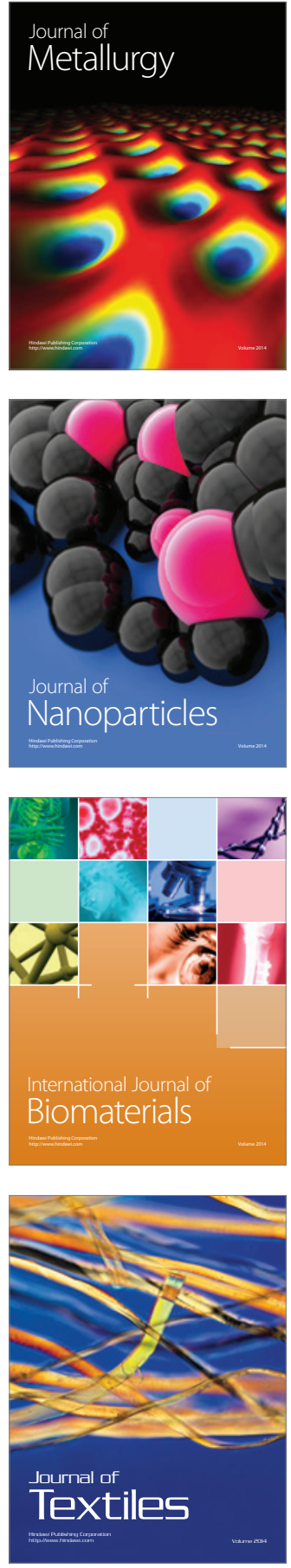